\title{
IDENTIFYING THE INTERSEX: SOCIETAL RESPONSES TO GENDERING THE INTERSEX WITH SPECIAL REFERENCE TO VIPAREETHAM
}

\author{
JIBIN JOSE $\mathbf{P}^{\mathbf{1}} \&$ SREENATH MURALEEDHARAN $\mathrm{K}^{\mathbf{2}}$ \\ ${ }^{I}$ M. Phil Scholar Department of English and Languages School of Arts and Sciences \\ Amrita University Kochi Kerala, India \\ ${ }^{2}$ Assistant Professor Department of English and Languages School of Arts and Sciences
}

Amrita University Kochi Kerala, India

\begin{abstract}
Post-modern era is characterized by gender revolution, as the conventional binary notions of gender are being redefined and restated.The public notion of gender identity has always been stigmatised in an orthodox society. But, the modern concept of gender spectrum offers an open platform that accommodates all the gender identities irrespective of their characteristic differentiation. It provides more social and political space to the gender minorities to express themselves in the public sphere, where they are highly marginalised. In this context, gender identity and its intricacies are subjected to critical discussions. This paper explores the gender identity construction of intersex people by analyzing the memoir titled Vipareetham. The present paper also attempts to reflect the societal responses to gendering the intersex and their social life.

KEYWORDS: Gender, Identity, Intersex, Identity Construction \& Mainstream
\end{abstract}

Received: Jun 23, 2017; Accepted: Jul 10, 2017; Published: Jul 21, 2017; Paper Id: IJELAUG201716

\section{INTRODUCTION}

Gender identity is undoubtedly the crux of the cultural discourse in the post-modern era. There is no identity crisis when a person's gender fits in the binary boxes of man and woman. But, what about those who fall out of this hetero normative divisions? How does the society label their identity? Or don't they have any identity at all? These questions have got much attention of late and are being cogitated again and again in the discourse of gender studies. These questions have to be suitably addressed for the benefit of a large number of individuals, whose gender identity is in question. This paper is a modest attempt to shed some light on the concept of gendering the intersex, a group of people who suffer marginalization in its multiple forms.

Gender identity is a concept that always remained an intensely stigmatic subject a decade ago. However, it has attracted critical attention and its intricacies are widely contemplated all over the world. In 2003, the Glossary of Terms Relating to Sexuality and Gender compiled by Henry A. Holmes, programme officer, Columbia Foundation, defined gender as a socially constructed classification that ascribes qualities of masculinity and femininity to people. In other words, gender refers to one's sense of self as masculine or feminine regardless of genitals. Mainstream notion of gender is defined as a binary system, where the society oppressively insists that everyone is to be raised either as male or female. This gender binary eliminates the possibility of other gender expressions and privileges those, whose gender perfectly fits into either of these categories over transgender, 
intersex and other gender queer identities.

Now a days, perspectives have changed, and gender is not considered as a hetero normative binary system, rather it is understood as a gender spectrum consisted of a variety of gender categories, which fall beyond the binary boxes of man and woman. Gender spectrum is an inclusive terminology accommodating all the gender deviants acknowledging their identity and difference. This novel thought acknowledges gender as a social and cultural construct that communicates to the society and culture in which the individual lives.

This paper is an Endeavour to explore the world view of adjudging gender as a socio-cultural construct and the societal riposte to gendering intersex people. It also deals with their social encompassment through the reading of a personal narrative written in Malayalam language. The memoir is titled Vipareetham told by Raju, an illiterate intersex and written by Unnikrishnan Avala.

In our society, the identity of an individual is decided not by the individual but, by the society. In fact, the individual has no right to make a statement regarding identity. Even if an individual claims that he/she belongs to a particular gender, the society will not heed to those arguments because those challenge the conventional norms of gender. As a usual practice, the gender of an individual is determined by the doctor at the time of birth by examining the infant's genitals. The physical structure of the genitals determines the gender of the individual. The life of people, who are born with characteristics that are different from the norms of hetero normative society becomes problematic here.

Gender identity of individuals refers to the deep sense of self with which they identify themselves. Realising one's gender identity and presenting oneself conforming to the approved gender regulations of the times, is expected of an individual to enjoy a 'normal' life in the society. Manifestation of gender identity is represented through gender expression which is a person's outward gender presentation, usually constituting personal style, make up, vocal inflection and body language.

Unlike the traditional conception of gender as male and female, now the terms refer to gender may include: man, woman, transgender, masculine, feminine and queer. The people who remain outside the classification of male and female develop a sense of identity at the point, where genitals are not the criteria for determining their gender. Feminist biologist Ann Fausto Sterling claims that labeling someone a man or a woman is a social decision. She argues: 'We may use scientific knowledge to help us make the decision, but only our beliefs about gender-not science-can define our sex' ( Fausto-Sterling,2000).

Raju is an adivasi, born in the Theekkady tribal colony, near Nilambur in Malappuram district, Kerala. Raju belongs to the 'Aranada' community, which is one of the most primitive tribal communities in India. Having lost parents in the early childhood, Raju earned livelihood as a hotel employee at Nilambur town.

Being a member of the tribal community, Raju suffered all the hardships that are common to the communitypoverty, insecurity, social subjugation, illiteracy, alienation etc. But he strived to live challenging all these hardships courageously. Raju's life experienced a dramatic turn at the age of eighteen, when one day he started to menstruate and the following medical examinations confirmed the presence of a uterus inside the body of Raju. This biological ambiguity and the subsequent difficulties associated with menstruation made his life more miserable and beyond the understanding of his 'primitive' thinking.

Raju's body bears both uterus and male genitals. The presence of these contrasting re productive structures in the 
same body makes his identity quite ambiguous and so he belongs neither to the category of male nor to that of female. As Raju is illiterate and does not have access to the worldly knowledge, he is not able to understand his anomalous biology in its true perspective and the intersex category to which he belongs. The only thing that he is sure about is the presence of a uterus that makes him menstruates.

Intersexuality is a set of medical conditions that features congenital anomaly of the reproductive and sexual system. Intersex people are born with 'sex chromosomes', external genitalia, or internal reproductive systems that are not considered standard for either male or female. The existence of intersex people shows that there are not just two sexes and that the ways of thinking about sex, that is, classifying all the individuals into the categories of male and female, is socially constructed. Individuals who are intersexed have bodies that are quite literally queer or 'culturally unintelligible' (Butler, 1993). The special issue of National Geographic Magazine (Jan. 2017) on Gender Revolution defines the term intersex as an umbrella term that describes a person with a genetic, genital, reproductive, or hormonal configuration that does not fit into typical binary notions of a male or female body.

Identity construction is one among the thrust areas where cultural discourse mainly focusses. Identity makes a call on the meaningful existence of an individual in the contemporary society. The individuals who are not able to establish a distinctive identity find it difficult to lead a comfortable life in the society. Raju's memoir Vipareetham also tries to put its focus on the problem of identity construction. Raju introduces himself as a person whose identity convictions are totally muddled. He exhibits his inability to fit his identity into the binary boxes of man or woman, the only two gender forms most probably he knows.

In a country like India, where anything that falls out of the hetero normative system gets an anomalous treatment, it is a challenging task for the gender variants to build up and establish their identity. Being an intersex and someone who is incognizant of the ambiguous biology of his physicality Raju fails miserably in the Endeavors of identity establishment. When a male or female person attempts to create a space of his/her own in the society, the process gets the support of the society and it will be regarded under the title of mainstream identity construction. But, when the gender variants attempt the same, the society intervenes and raises many challenging hurdles to jump over to embrace their internal sense of self. People usually think only about the identity of man or woman and this classification has strong roots in the social construction of gender. But beyond this, there exists other gender forms which belong to the LGBTIQ groups. Thinking beyond this socially established identity pattern and exploring the identities of the differently gendered has become one of the significant aspects of gender writing in the postmodern era.

In the memoir, Raju reveals that he confronts all these challenges in its fullest level. But still, he cannot be successful in recognizing and establishing his identity. Raju was born and brought up as a male until he turned eighteen, the age at which he started to menstruate. After the medical examination, he understood the fact that he bears a uterus in his body. After this realization, his identity posed a big question mark before Raju. He is absolutely bewildered about his gender as he says:

Neither a man nor a woman, in between these two.

I am not at all clear.

That's the difficulty in my mind...(Raju and Unnikrishnan, 2012).

The public intellect is so orthodox in its understanding and practices that an individual born with a sexually 
ambiguous body finds it difficult to mark a space in the mainstream society. If the person belongs to a socially and financially backward community, then the sufferings and the discriminations get multiplied several times. The social responses to people who are born with an uncharacteristic sex are often not so favorable. Raju experienced a series of sufferings throughout his life right from the beginning in the form of sexual abuse, social exclusion, alienation and physical and mental torture. But, after the matter of his ambiguous identity gets publicized, he was subjected to various kinds of sexual abuse even more frequently. Even in his hut inside the forest, he did not feel secured. Individuals of the so called'cultured and civilized' society searched his hut frequently to get hold of him. Raju says:

I was taken by people to lie with them the next day onwards I reached the hotel. It started from the hotel. After this information got publicized, every night, people would come and take me forcibly to satisfy them. I tried to resist at first. But it was in vain. Then I became used to it. People who used me included the rich and the anti-social miscreants (Raju and Unnikrishnan, 2012).

Through these words, Raju expresses his helplessness in resisting the sexual and physical attack on him. His words indicate the attitude of the mainstream society to the people who belonged to the intersex community. Raju was absolutely helpless and became really shocked, when he heard the news that he is neither a complete man nor a complete woman and cursed the gods for doing the injustice to him. As Raju says; I even couldn't cry as no sound came out of my throat (Raju and Unnikrishnan, 2012).

Raju is a representative of the doubly marginalized. The social community to which he belongs is a marginalized one like his gender community. Though there are many categories like LGBTIQ under the term gender variants, the intersex people do not get much representation in the social, cultural and literary domains when compared to other categories. Finding the reasons behind this is a way to make more social and cultural interventions in the life of these people. In this perspective, Raju's Vipareetham has attained great significance.

Bodies that are sexually ambiguous challenge the existing binary understandings of sex and gender. People, whose experience of gender is different from what has been imposed on them at birth, face wide spread stigma and discrimination. In most of the cases, the intersex people do not need a medical intervention to survive. Though the presence of ambiguous sexual organs, indeed problematizes binary understandings of sex and gender, the majority of the intersexed children do not require medical intervention for their physiological health (Diamond and Sigmundson, 1997). While majority of the intersex conditions are found to be physiologically not dangerous to health, some cases do require surgical or hormonal interventions for reasons of the individual's health. But, most often medical interventions are carried out on intersex individuals on the assumption that without the medical altercations of genitals intersex people will lead a life of alienation and disappointment. Majority of intersex individuals undergo medical interventions to get into 'normalcy' just to avoid the social stigma.

The medical intervention could be called "unwanted" took place in Raju's case too. Persuaded by certain external forces of vested interests, Raju underwent surgery to correct the ambiguousness of the body because he desperately desired to avoid the pain and the physical hardships at the time of menstruation. But, Raju could not go for the second surgery which was inevitable to complete the transition from male to female. Raju's ignorance played a significant role in landing him in the present dilemma where now he lives with a body that is more ambiguous in its structure with male genitals removed and internally having a uterus. Raju's inability to take independent decisions compelled him to rely on others' help which was not always offered in the right earnest. Consequently, he failed to make a true call on his physical and 
gender self.

Diversity is the law of nature and no one has the right to turn a blind eye to it. In the present era of gender revolution, the concept of gender gets more and more diversified. The conventional notion of binary system of gender is being redefined, and now it gets developed into the status of a gender spectrum that accommodates all variants of gender identities. Like any other person, gender identity of an intersex is to be determined by the individual itself. Intersex people have an ambiguous physical anatomy and it differs from individual to individual. They add more diversity to the mankind. But they are highly marginalized gender minority. Every intersex life is a long struggle to express and experience the identity that is original. Intersex people also can identify their gender and feel their sense of self, which may not conform to the accepted norms of the mainstream society. But, it is justifiable to accept them as they present themselves since gender is more fluid and identity is more flexible. It is illogical to demand them to change their body for the sake of the society. Though Raju has a strong desire to establish a distinctive gender identity, the circumstances and the society in which he lives do not support him. Through his experiences, Raju reveals to the world the social responses to those who are born out of the established gender binary i.e., man and woman. Education is the key to come out of all kinds of oppressions and discriminations. So, all the gendered variants including intersex people should be given education and social support. The main stream society should take pride in educating and supporting these people rather than discriminating and exploiting them. Moreover they should be given the freedom to perform their gender since gender is performance as argued by Judith Butler.

\section{REFERENCES}

1. Blackless, M., Charuvastra, A., Derryck, A., Fausto-Sterling, A., Lauzanne, K., \& Lee, E. (2000).How Sexually Dimorphic Are We? Review and Synthesis. American Journal of Human Biology, 12, 3.

2. Butler, J. (1990).Gender trouble: feminism and the subversion of identity. New York: Routledge.

3. Butler, J. (1993).Bodies that matter: On the discursive limits of "sex". New York: Routledge.

4. Diamond, M., \& Sigmundson, K. (1997). Management of intersexuality: Guidelines for dealing with persons with ambiguous genitalia. Archives of Pediatric Adolescent Medicine,151, 1046-1050.

5. Fausto-Sterling, A. (2000).Sexing the body: Gender politics and the construction of sexuality. New York: Basic Books.

6. Goldberg, S. (Ed). (2017). Redefining gender. National Geographic Magazine, 4 (6), 24-25.

7. Holmes, H. A. (Comp).(2003). Glossary of terms relating to sexuality and gender. Retrieved from https:// www.deltacollege. edu $>$ Gs- Terms

8. Preves, E. S. (2002). Sexing the intersexed: An analysis of socio cultural responses to intersexuality. Signs, 27 (2), 523-556.

9. Raju, \& Unnikrishnan A. (2012).Vipareetham. Kottayam: DC Books.

10. Sinha, T. (2015).Identity construction of the third gender in the truth about me.MIT International Journal of English Language and Literature, 2 (2), 63-68.

11. Turner, S. S. (1999). Intersex identities: Locating new intersections of sex and gender. Gender and Society, 13(4), 457-479.

12. Wilson, B. E., \&Reiner, W. G. (1998).Management of intersex: A shifting paradigm. Journal of Clinical Ethics, 9 (4), $360-369$. 
